Article

\title{
Beyond Making and Unmaking: Re-Envisioning Sacred Art
}

\author{
Daniel Gustafsson \\ Centre for Lifelong Learning, The University of York, Heslington, York YO10 5DD, UK; \\ dg.philokalia@gmail.com
}

Received: 16 December 2018; Accepted: 28 January 2019; Published: 31 January 2019

check for updates

\begin{abstract}
This paper engages with predominantly Eastern Orthodox thinkers in reassessing the conditions under which sacred art may be possible today. The sacred has both ontological and cultural aspects. An artwork is sacred, firstly, by virtue of partaking of transcendent realities; and secondly, by being embedded in a worldview which allows the work to be made and received as sacred. Drawing on the thought of Philip Sherrard, the paper suggests that current conditions are characterised by cultural forgetting and the loss of such a metaphysical worldview. This paper proposes that the possibilities of sacred art must be rediscovered from within the practices of particular arts; and that this goes hand in hand with the rediscovery of a sacred ontology and of a Christian understanding of freedom. The paper will follow David Bentley Hart in affirming a theological understanding of freedom-as the orientation towards, and the attainment of communion with, ontological goods-against the prevalent postmodern and ultimately nihilistic notion of freedom as spontaneous volition. It is crucial, therefore, to also identify those transcendent goods towards which art may fruitfully be directed. In this light, the paper proposes the need to revise our concepts of matter, form, and, above all, beauty.
\end{abstract}

Keywords: sacred; art; freedom; beauty

\section{Introduction}

This paper engages with predominantly Eastern Orthodox thinkers in reassessing the conditions under which sacred art may be possible in the context of Western culture today.

The sacred has both ontological and cultural aspects. An artwork is sacred, firstly, by virtue of partaking of transcendent realities; and secondly, by also being embedded in a worldview and way of life which, by acknowledging those realities, allows the work to be made and received $a$ sacred.

Drawing on the thought of Philip Sherrard, the paper suggests that current conditions are characterised both by cultural forgetting and the loss of such a metaphysical worldview. A change in the material conditions of art's production and reception cannot alone account for the crisis of sacred art; the change has happened also on the level of intellect and spirit. For this reason, any revival of sacred art cannot simply be a matter of contextual and material redistribution. What is needed is a genuine restoration or revision of our understanding of art and the sacred alike.

This paper proposes that the possibilities of sacred art must be rediscovered and reclaimed from within the practices of particular arts, and that this goes hand in hand with the rediscovery both of a sacred ontology and of a Christian understanding of freedom.

While, as Davor Džalto has shown, even postmodern conceptual art may stimulate fruitful theological reflection, not least on the nature of human freedom and creativity, it is important to consider whether such art has any ability to reorient our lives towards the sacred. Considering conflicting models of freedom, the paper will follow David Bentley Hart in affirming a theological understanding of freedom-as the orientation towards, and the attainment of communion with, 
ontological goods-against the prevalent postmodern and ultimately nihilistic notion of freedom as spontaneous volition. As long as both artists and audiences labour under postmodern notions of freedom, the paper argues, no sacred art is possible.

It is crucial, therefore, to also identify and credibly articulate those transcendent goods towards which the free creation of art may fruitfully be directed. In this light, the paper proposes the need to revise our concepts of matter, form, and, above all, beauty. The paper urges that we understand matter as both imbued with cultural meaning and as potentially spirit-bearing; that we understand form in terms of discipline and open-ended relation; and that we understand artistic beauty, not as immanent self-sufficiency or formal perfection, but as the manifestation of the divine gift.

Freedom can be understood in Christian terms as the freedom of the creature to flourish in the image and likeness of God; in this light, the paper suggests that also the free creation of an artwork - and the regenerative labour of artistic practice-attains its flourishing when it becomes in some manner iconic, sacramental, and theophanic.

\section{The Possibilities of Sacred Art}

Was music once a proof of God's existence?

As long as it admits things beyond measure,

That supposition stands. (Heaney 2015, p. 58)

Every artist implicitly affirms a world irreducible to its material parts. Any attempt to explain the arts in purely materialist terms, whether Marxist, evolutionary, or neurophysiological, entirely fails to do justice to the phenomenology—let alone the ontological implications—of both its creation and its reception.

"Creativity in the world is possible," claims Nicolai Berdyaev, "only because the world is created." (Berdyaev 2009, p. 129). The point is vital. Without a sense of the created world as having its origin in, and existing in relation to, the uncreated-without the world being open to, and dependent on, a reality that ontologically transcends and is other than the world-it is difficult to intelligibly entertain the possibility of human creativity as more or other than immanent procreation, re-creation, and re-organisation. "If there had not been a divine creative act," as Berdyaev argues, "in which something which had never been before was created, then the creative act in our world would be quite impossible." (Berdyaev 2009, p. 128).

If art is to have any ontological significance, we need a sense of human creativity as synergetic with the divine.

This would also mean that a sacred purpose and orientation is the true and natural mode of art; that art draws upon, and is directed towards, the uncreated source of all form, beauty, and being. Indeed, I will argue, not only that an ontology of participation, whereby the finite and material may partake of the spiritual and transcendent, is necessary to accommodate our great works of art, but that creative practice itself urges us to rediscover such an ontology from within the artistic traditions.

It is not necessary here to attempt a definition of sacred art; but it should be emphasised from the outset that sacred art is art that does not allow its audience to rest within, or retreat into, secular, materialist, or immanent models of explanation. In current circumstances, therefore, it is unsettling of prevailing notions. It is an art that asks us to revise our view of the world and reorient our lives towards transcendent goods-ultimately, towards God.

\section{The Loss of Sacred Contexts}

The making of art, if Berdyaev is right, is a cosmic event. It is also, of course, a cultural event. All art is contextual; it subsists and operates within specific conventions, practices, and shared understandings. This context is both cultural and ontological. It matters which worldview is assumed in the work's production and reception. These claims are perhaps especially true with respect to sacred 
art, not least the tradition of icon-painting. Pavel Florensky is emphatic: if you remove an icon from the liturgical, cultural, and ontological context of the Church, it ceases to be an icon.

Today, in a postsacral as well as postsecular world, we are rather in a situation where the church has, as it were, been removed from the icon. Intellectual and institutional bases for a sacred worldview are progressively dismantled or discredited. This loss of a sacred orientation in society would seem to result inevitably in the loss of sacred art. Such is the concern motivating Philip Sherrard in The Sacred in Life and Art. Sherrard was a poet, translator, and lay theologian. Disillusioned with the emotional, intellectual, and spiritual climate of the West, Sherrard's gradual conversion to Eastern Orthodoxy was sparked by his discovery of the poetry of George Seferis. In his admittedly rather sweeping analysis of the Western artistic tradition, Sherrard shows commonalities both with the Catholic artists Eric Gill and David Jones and with the Orthodox priest and scholar Pavel Florensky. For all these thinkers, artistic and spiritual decline go hand in hand. Thus, Florensky categorically claimed: "From the Renaissance on, the religious art of the West has been based upon esthetic delusion." (Florensky 1996, p. 67). In The Sacred in Life and Art, the culmination of Sherrard's reflections, he laments in particular the disastrous division between art and aesthetics, on the one hand, and metaphysics or theology on the other. First published in 1990, the book's diagnoses are arguably yet more acute today.

We should ask, with Sherrard, what power art possesses, in current circumstances, to resist a trend towards the all-encompassing desacralisation of human culture and conceptions. This is not simply a theoretical question. For the artist, it must also be answered in practice. Sherrard makes it clear that we must change our way of life. This should entail our way of making things as well as our way of doing things. At the same time, new action and new creation must be underpinned by new understanding. An art of genuine sacred orientation is needed; "yet given that an artist today would like to produce an art of this kind, is it possible for him to do so?" (Sherrard 2004, p. 36).

Sherrard stresses the all-pervading alienation that characterises our "mechanized, industrialized, dehumanized and desacralized world."1 Art that is the product of such a world, that tacitly or openly affirms it, cannot alert us to-indeed, cannot but alienate us further from-the sacred. What, then, is the nature of art in such a world? What presuppositions govern its making and reception?

For Sherrard, these presuppositions are, broadly conceived, those of the humanist aesthetics championed by Herbert Read. The model derived from Read (if not always in line with his own vision) is art in relentless pursuit of originality; a pursuit which, untutored by the aesthetic, moral, and metaphysical ordering of goods, leads to increasingly arbitrary, wilful and transgressive expressions.

"The new-that which is innovatory-becomes a value in its own right," Sherrard explains, "and there can by definition be no authentic creativity without innovation, either in style or theme but preferably in both." ${ }^{2}$ At the same time, since it is premised upon secular assumptions, "art and creativity cannot possess therefore any significance other than that which can be formulated quite adequately in hedonistic ('I know what I like'), sociological, scientific or psychological terms." 3

In its stress on freedom from traditional forms, Read's model risks resulting in a lack of coherent continuity within the arts, inimical to the transmission, from one generation to the next, of both practical and theoretical wisdom. It also risks making any distinction between the creative and destructive, the vital and the vicious, all but impossible. "Ultimately," Sherrard comments, "art is to be regarded as the symbolic form of a specific, extended or heightened inner experience, though whether this experience is archetypal or merely the secretion of a morbid or corrupt subjectivity gone haywire it is impossible to assess." 4

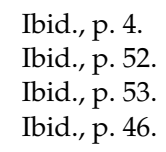


With no moral and metaphysical ordering, Sherrard argues, the ideas and images that govern the mental life of humanity "represent more and more an ontological perversion." 5 When such mental images "inform and animate" our art, "they produce not a revelation of the intrinsic sacredness of things, but a dislocation, a distortion that vilifies the very idea that life and art should be a bringing to birth of the beautiful and holy." ${ }^{\prime 6}$ Artworks now help to perpetuate and vindicate a view of the world in which our alienation from transcendent and ontological goods is natural.

This is the crux of the matter: for much of modern and contemporary art, it has become not only the default position, but even the eagerly assumed mission of the artist to be, not a steward of the sacred, but an agent of desacralisation. The obstacle to any sacred revival in the arts, then, is not only entropic cultural amnesia, but a wilful negation of the perennial practical wisdom that has animated human making from classical times.

\section{Theoretical and Practical Knowledge}

A key assumption of Sherrard's is that the decline in art is precipitated by a loss or forgetfulness of traditional metaphysical awareness. He insists, thus, on theoretical knowledge as a "precondition of knowing in an experiental sense" ${ }^{\prime 7}$; and he argues that we must first reclaim a spiritual life before we can hope again to create a spiritual art. "Artists whose way of life does not include the experience of spiritual realities or even the acknowledgement of these realities," he maintains, "are simply deluding themselves when they talk of being in the front line in a cultural battle against [ ... ] the vast inhumanity that typify our contemporary societies: they are the servants and victims and instruments of exactly the influences that have shaped these societies." ${ }^{\prime 8}$

We must be careful, nevertheless, not to suggest that the poem or painting is simply instrumental in the uttering or illustration of an antecedent proposition. Nor should we assume that any poetic treatment of sacred doctrine amounts to sacred poetry, or that any painting of a holy subject results in a holy painting.

There is a risk of Sherrard overestimating the role of antecedent knowledge, and so of underestimating the ability of artistic labour to, not only generate knowledge, but also constitute a mode of knowledge. The painter Ian McKeever's testimony is valuable here: “'In painting a painting one does not set out to paint what one knows, but rather tries to touch those things which one does not know and which perhaps cannot be known.'" (McKeever 2009, p. 24).

We should emphasise that, in the case of art, knowledge can and must be gained from praxis and participation. Any medium — poetry, painting, music - possesses a rich repository of practical wisdom that is only accessible through active immersion, as a result of keener discernment and increasingly refined modes of expression. It must be stressed, therefore, that our modern and postmodern forgetfulness is not only of the metaphysical, but also of the artistic, traditions: their roots, their resources, and their regenerative potentials.

It is important to challenge the pervasive assumption that artistic or authorial intentions are always antecedent to the creative act. In contrast, we can conceive of intentions as simultaneous with composition; as those of the sculptor who both moulds and manipulates his material and at the same time discovers the form his creation will take.

The assumption of antecedence can be disputed by the testimony of many authors and artists. Rowan Williams' comments on David Jones may suffice to indicate the importance of this type of experience: "the half-apprehended consonance of impressions out of which an artwork grows has to be realized in the process of actually creating significant forms which, in the process of their embodiment,

\footnotetext{
Ibid., p. 14

Ibid., p. 15.

Ibid., p. 131

Ibid., p. 34.
} 
in stone, words, or pigment, uncover other resonances, so that what finally emerges is more than just a setting down of what was first grasped." (Williams 2005, p. 71).

It is in the dialogue between maker and medium-or perhaps between maker and the mystery of reality, as pursued through a particular medium — that the artwork becomes what it is, and that its unique meanings are realised. This experience is succinctly evoked by T.S. Eliot in Little Gidding:

Either you had no purpose

Or the purpose is beyond the end you figured

And is altered in fulfilment. (Eliot 1944, p. 36)

\section{The Postmodern Challenge}

This has bearings, as we shall see, on how we think about the matter, form, and beauty of artworks. It also bears on certain tendencies of postmodern art, motivated as these are by a reaction against previous prevailing ideas of authorship and creative autonomy.

In light of the above examples, we can understand the pursuit of varying degrees of nonagency or unmaking in the artistic process. Davor Džalto, in The Human Work of Art, has admirably embraced the opportunity afforded by postmodernist art to reassess our conceptions of creativity, to move away from "modernist constructs of art and individuality [so as] to understand the very existence of the human being." (Džalto 2014, p. 103).

Yet the radical move towards nonagency may be motivated, at least in part, by overestimating the degree of autonomous agency in more traditional art. As the above examples indicate, and as further examples below will elucidate, the author or artist is less in control than is often assumed even in the case of traditional forms of art. Insofar as this is right, rather than jettisoning the practice of such art, the impetus should be to seek a deeper understanding of the implications of the synergetic nature of artistic creation.

Džalto, not unlike Sherrard, rightly observes that the modern notion of creative individuals, producing original works that bear marks of their unique "psychophysical characteristics and potential" ${ }^{9}$ is problematic; for, "from a positivistic perspective, human creativity could be reduced to a complex web of various physical and chemical factors [which does not] represent any ontologically free activity of humans." 10 This last remark, however, should also serve to make us wary of the mechanisation and depersonalisation actively pursued by much postmodern art.

It is clear that postmodern art can make us think afresh about the production and consumption of art. For the purposes of this paper, however, the question must be asked: what power do these postmodern works have to reorient our vision towards the sacred and divine?

On Sherrard's assessment, even a poet like Gerard Manley Hopkins, for lack of a surrounding metaphysical culture, "cannot reveal to us that ours is a sacred universe" (Sherrard 2004, p. 146). What hope is there then for Warhol or Yves Klein? Are their works not too deeply embedded in the secular narrative to be able to show us a way out of it? Hopkins, arguably, can do more; at the very least, his verse should awaken us to the notion that perhaps ours is not an entirely desacralized universe. Further, Hopkins recommends a theological reading; indeed, his poetry requires a theological framework to yield its full meaning. More recently, the poetry of David Jones would seem to make similar demands. His masterpiece, The Anathemata, makes sense only within a sacramental ontology and therefore does something to show the value and validity of such an ontology.

The works of Warhol and Duchamp can raise questions about the nature of art and creativity, which in turn may engender theological answers, but there is nothing 'in' or 'about' these works themselves that urges us accept a sacred worldview. It is also fair to assume that a vanishingly small 
section of the artworld (as of the general public) labours under theological conceptions. Indeed, while the changing nature of art appears amenable to Džalto's theological analysis, it is also the case that most of the theoretical and philosophical discourse accompanying this art appears resolutely anti-theological. There is in fact a tremendous risk that this change in art is received as a further move away from any need for a notion of the sacred.

An emphasis on automatic process, on ready-mades, on impulse and stream-of-consciousness-in short, any attempt to bypass conscious creative agency and embrace 'the death of the author' - can be seen to play into the hands of a mechanical and desacralised metaphysics. At the same time, a corollary trend can be seen; in a world vacated or inherent meanings, a new version of the arbitrary imposition of authorial subjectivity. This should urge us to consider the idea of freedom operative among artists, critics, and students of art today.

\section{Models of Freedom}

While a discussion of freedom is rather absent from Sherrard's analysis, it is central to Džalto's engagement with modern and contemporary art as well as to David Bentley Hart's diagnosis of modernity. Given its central importance in the contemporary cultural context, a consideration of freedom is relevant also for the purposes of this paper insofar as it bears on the issue of art and artistic practice.

It is right of Džalto, like Berdyaev, to affirm that our creative freedom is a mark and mode of the divine image in us; that we are beings "capable of creating, at least in some sense, out of nothing." (Džalto 2014, p. 33). We should indeed affirm that we create 'out of freedom', and not out of necessity; that our creation-both the act and the work-may therefore partake of the uncreated; and that something new therefore enters the world from beyond the finite. This means that the creative act itself gives the lie to the materialist presumptions of much contemporary art and theory.

It is equally vital, however, to maintain that our growth in the divine likeness is conditional upon the right and fruitful use of this creative freedom. Our freedom can be used creatively or destructively, to illumine and affirm those transcendent goods in which it has its origin and end, or to occlude and negate these. This vital point sets the pursuit of sacred art and life squarely against, not only the aesthetic, but the moral and metaphysical certitudes of modernity.

"We live in an age," writes David Bentley Hart, "whose chief moral value has been determined, by overwhelming consensus, to be the absolute liberty of personal volition"; and "any society that believes this must, at least implicitly, embrace and subtly advocate a very particular moral metaphysics: the unreality of any value higher than choice, or of any transcendent Good ordering desire towards a higher end." (Hart 2009, p. 1).

This is a nihilist metaphysics; because, as Hart makes clear, "For us to be as free as we possibly can be, there must be nothing transcendent of the will that might command it toward ends it does not choose or even fabricate for itself, no value higher than those the will imposes upon its world, no nature but what the will elects for itself." (Hart 2017, p. 314). This gives rise, in turn, to a nihilistic aesthetics, characterised by "explicit depictions of sex and violence" and "mindlessly brutal forms of entertainment" (Hart 2009, p. 77); by what Sherrard has already called "the search for increasingly violent forms of emotional or physical sensation." (Sherrard 2004, p. 34).

Crucially, Hart notes the initially theological origin of our current notion of freedom, as a product of late scholastic voluntarism and the reduction of God to pure power, before also claiming that it leads, almost inevitably, to atheism; "all genuinely modern stories of liberation, presuming as they do some version of this model of freedom, perhaps must terminate in a final rebellion against God: for he is the one intolerable rival who must be slain if humanity is ever truly to be free." (Hart 2017, p. 316). While the drama of this rebellion has been enacted in much modern art, perhaps most profoundly by Wagner, this model of freedom is inherently incommensurate with sacred art.

In this light, some further questions can be posed to the kind of art investigated by Džalto. For example, does Duchamp's practice of naming or renaming objects bring forth something essential or 
connatural to those object, or is it an arbitrary labelling? Does it not threaten, in that case, to subsume the labelled object under a voluntarist metaphysics? Rather than inviting us to celebrate the glory of the created and uncreated, do these practices tempt us with nihilism? Do they, in fact, suggest that the human will is the source of all value?

Conceptual art is problematic if the artist can decide, and needs to tell the unwitting audience, what a piece means. This legitimises again the so-called intentional fallacy, authorising the projection of a personal language. Meaning becomes something imposed by will upon inherently meaningless materials, rather than something emerging out of a responsiveness to those realities. Far from getting us away from authorial individualism, this aggravates it.

Conceptual art, then, can be seen to instantiate the same tendencies that Florensky identified in the particularly Protestant development of engraving: "the artistic freedom to arbitrarily choose the surface", the imposition by "the supposedly Pure Reason" of its "graphic schemata of reality [... ] on materials that have nothing in common with them"; a destructive rather than creative activity, because "in exercising its freedom of self-determination, it violates the self-determination of the world; while, in proclaiming its own law, it thinks it unnecessary to attend to that law whereby all things in creation become authentically real." (Florensky 1996, pp. 111-12).

We risk, in short, ending up with a kind of voluntarism of the artworld, epitomised by the phrase 'it is art because I say so'. Instead, we want to be able to say something like this: it is art because, responsive to the revelatory and regenerative potentials of a given medium, it participates in the act of Creation; because, as C.A. Tsakiridou may say, it makes a thing or an aesthetic object that in itself hypostasises being.

For this to be possible, we need another ontological picture that can also harbour another realisation of freedom. The alternative model, most succinctly formulated by Hart, is this: "We are not free because we can choose, but only when we have chosen well." (Hart 2009, p. 79). On this classical and Christian understanding,

true freedom is the realization of a complex nature in its proper ends, both natural and supernatural; it is the power of a thing to flourish, to become ever more fully what it is. But to think of freedom thus, one must believe not only that we possess an actual nature, but also that there is a transcendent Good toward which that nature is oriented. To be fully free is to be joined to that end for which our natures were originally framed, and whatever separates us from that end-including even our own personal choices-is a form of bondage." (Hart 2017, p. 313)

Hart stresses "that only a society ordered towards the transcendental structure of being-towards, that is, the true, the good, and the beautiful-is capable of anything we might meaningfully describe as civilization, as it is only in the interval between the good and the desire wakened by it that the greatest cultural achievements are possible." (Hart 2009, p. 90).

The need for a teleological, as opposed to a voluntarist, understanding of freedom was recognised also by Berdyaev. The latter, Berdyaev calls "childish, slavish freedom." (Berdyaev 2009, p. 290). Its nihilistic implications are evident: "Negative freedom, freedom as arbitrary free will, is freedom without content and void. To desire freedom for its own sake, freedom without purpose or content, is to desire emptiness, to turn away towards non-being." (Berdyaev 2009, p. 147). "A mature freedom," on the other hand, "a freedom with real content, predicates the maturing and uplifting of the inner man"; such freedom "has cosmic content and intention towards the world's goal: it is the opposite of wilfulness." (Berdyaev 2009, pp. 290-91).

Such freedom is the freedom of creation and regeneration; it is the freedom required for, and realised in, sacred art. Voluntarist freedom, meanwhile, is inherently iconoclastic. We see it in the incessant defacement, defecation, and desecration in contemporary art. As Roger Scruton notes, "It is not merely that artists, directors, musicians and others connected with the arts are in flight from beauty. There is a desire to spoil beauty, in acts of aesthetic iconoclasm." (Scruton 2009, pp. 173-74). 
Sherrard is quite right, therefore, to say that religious or metaphysical concerns are far from irrelevant to the practice of art: "Art, like life, has one range of possibilities and purposes when you recognize and try to live in accordance with beliefs of a religious nature and quite another when you do not." (Sherrard 2004, p. 47) To put it bluntly, if we dispose of our traditional icons and replace them with sheep cut in half and canvases covered in shit, what does this do to our sense of who we are and can be?

Hart argues that modern freedom ultimately is "incompatible with a Christian view of the human being." (Hart 2017, p. 322). Arguably, so is much of modern and contemporary art. I suggest that insofar as art labours under such an idea of freedom, it cannot produce sacred works. Any sacred art must be situated within a metaphysics capable of accommodating a classical Christian model of freedom.

\section{Matter and Meaning}

The only way to escape alienation and desecration in theory, and the only chance of overcoming these in practice, is to have recourse to a theological ontology of participation. We need, as Hart and Sherrard as well as Džalto prescribe, a vision of the created as partaking of, and abiding within, the uncreated. Any genuine pursuit of sacred art today must operate within such an ontology. Crucially, such an apprehension of reality is implied by and enshrined within the artistic traditions. To discover the true potentials of art is to discover the only worldview in which such art is possible: an ontology which allows us to affirm the sacred potential, not only of the form and beauty of our art, but also of its very materiality.

Sherrard, giving his working definition of the sacred, notes: "We are at once in the midst of things. The sacred is something in which the Divine is present or which is charged with divine energies." (Sherrard 2004, p. 1). It is vital to stress that the created work or thing does not merely signify, but indeed partakes of, the uncreated or divine; so that this work itself is irreducible to its material 'thingness', because it is what it is only in relation to that which transcends it. This is at bottom, of course, a sacramental and iconic understanding of reality. On this understanding, the very corporeality of an artwork is integral, not antithetical, to its potentially spiritual aspects.

We know, not least from our experiences of art, that material things can be both mind-changing and spirit-bearing. The 'dematerialization' embraced by much postmodern art can therefore be challenged in light of what Andrew Louth, with Sergei Bulgakov, calls 'Christian materialism'. Already in John Damascene's defence of icons, of course, a vindication of sacred art entails an emphatic vindication of matter. Such a vindication is crucial for the sacramental, in art no less than in liturgy. As Louth reaffirms, "matter is God's creation; it is not to be despised; it is precious; it is capable of disclosing to us the creative power of the God who created it. It is only because we are material beings that we can participate in God in the Eucharist, a privilege denied to purely spiritual beings such as angels." (Louth 2013, pp. 113-14).

Matter can bear the countenance of divine beauty. All sacred art, in some manner and measure, rests on this assumption. Thus, even a contemporary painter like McKeever can both stress the materiality of his artworks and affirm their ambition to manifest a more-than-material light. "'A painting should light from inside itself,"' he claims. "'You should feel the emanation of light. I do not want to depict light but to have the painting giving light."' (McKeever 2002, p. 12). This hope should be heard within the context of an ontology in which genuine transfiguration is possible. McKeever's paintings themselves, which are both elemental and angelic, testify to the possibility of matter becoming transparent to spirit.

What constitutes the matter of art is not, of course, straightforward. The example of poetry highlights both the ambiguity of this concept and its vital importance. Poetic artefacts are of an elusively nonmaterial kind; but they do rely on the 'matter', broadly construed, of the culture and language in which they operate. As both the practice and theory of David Jones make clear, every 
artist, whether visual, literary or other, relies upon handed-down cultural deposits no less than the raw materials of a medium.

Poetry certainly depends for its meanings on shared languages, both of the poetic tradition and of the wider culture, themselves conditioned by previous acts and artefacts of meaning-making. Given this human history, we may say that poetic matter itself is articulate. This relates back to the idea of creativity as discovery, of intention as in some sense synonymous with, rather than antecedent to, the act of making something in a particular medium. A classic evocation of this insight is given in Pasternak's Doctor Zhivago when the poet-physician experiences "what is known as inspiration":

The primacy no longer belongs to man and the state of his soul, for which he seeks expression, but to the language in which he wants to express it. Language, the homeland and receptacle of beauty and meaning, itself begins to think and speak for man and turns wholly into music, not in terms of external, audible sounds, but in terms of the swiftness and power of its inner flow. Then [ ... ] flowing speech itself, by the force of its own laws, on its way, in passing, creates metre and rhyme and thousands of other forms and constructions, still more important, but as yet unrecognised, unconsidered, unnamed. (Pasternak 2011, p. 390)

Matter and medium are themselves wellsprings of meaning, potentially charged with spirit. Language is not a lifeless instrument, nor some blank slate for arbitrary impressions and impositions; so far from being wilfully made to mean whatever a particular speaker wants it to mean, language itself is the prime mover, and the poet its mouthpiece.

We should not underestimate the extent to which a shared language must exist also for conceptual art to 'come off' as successful works or events at all. The conceptual artist, no less than the painter or poet, manipulates a repository of accessible meaning-charged 'matter'; in this case, the conceptual baggage of the history of art itself, as well the expectations of its contemporary practitioners and public. Insofar as any artwork attempts to realise its autonomy from shared meanings, we should worry about its ability, simply put, to be meaningful. One aim of art should be, arguably, to achieve enduring forms of meaning that can also sustain meaningful forms of life.

\section{Form}

We see in the excerpt from Pasternak the importance also of form, broadly conceived, as indispensable to creative fruition. Now, to appeal to the importance of form is not to endorse 'old' metres, manners, and methods (whether in poetry, painting or other arts), but to insist on the making of a 'thing' that has both integrity and allusive power; a thing that 'comes alive' as what it is, within the given parameters of its particular medium, while also existing in dynamic relations to other works and realities.

It was a repeated dictum of David Jones' that to make two marks is at the same time to make a third; namely, the relation between the other two. It is this invisible third mark which is the source of aesthetic value and meaning within the work, which grants the work its 'significant form' (to borrow a phrase from Fry and Bell). We may speak, with Tsakiridou, of an "aesthetic object" constituted by "dynamic relationships" of "aesthetic elements such as line, hue, tonality, texture, saturation, shape, form, etc." (Tsakiridou 2013, p. 117).

A commitment to form is crucial on a sacramental worldview. Art is implicated in a sacramental ontology by realising, as Jones puts it, the re-presentation of one thing or reality 'under the form' of another. So that a form, thus understood, is neither a self-sufficient entity nor the immanent closure of meaning, but, on the contrary, a mode of radical openness to an overabundant reality. A work receives its coherence and articulacy, therefore, not only through its internal dynamics, but also through relations to realities outside itself, in the sense of both a cultural and an ontological context.

For the contemporary Greek painter and iconographer, George Kordis, the "lines, colours, movements, etc." of an artwork are all understood as "energies" which "must be reconciled and exist in a [... ] balanced dynamic state." At the same time, his "painting aims at creating an embracement 
between the object and the spectator." As such, it both "depicts" and realises a relation between the object and the subject. For Kordis, ultimately, the artwork may thus serve to realise a "state of love", "where the boundaries are lost, and life is an eternal communion." (Kordis 2019). This is an artistic and spiritual vision both in tune with the Orthodox tradition and sensitive to the problems and possibilities of a particular artistic medium in contemporary practice.

Form is not simply a prior constraint, arbitrarily imposed on artistic activity, but a framework emerging as a result of responsiveness to (and within) a particular medium; to (and within) a material culture; to (and within) a spiritual reality. An artwork subsists in a network of analogies.

As the example of Doctor Zhivago shows, when creativity is realised as responsiveness, form and freedom go hand in hand. An artist is, above all, a steward of meaning. He realises his own freedom, and the work itself achieves its liberty from the arbitrary, precisely in the service of, and communion with, transcendent goods. Art, therefore, makes virtually self-evident the idea that genuine freedom is possible only through constraints. The implications for art of Hart's proposed model of freedom is also clear from this argument:

The form, as Michelangelo used to say, is liberated from the marble. In this way, precisely through accepting freely the constraints of a larger social and moral tradition and community, one gives shape to a character that can endure from moment to moment, rather than dissolving in each instant into whichever new inclination of appetite or curiosity rises up within one. One ceases to be governed by caprice, or to be the slave of one's own liberty. (Hart 2009, p. 79)

The creative life is more than analogous to the religious life, as the examples of the greatest religious artists and poets testify. It must be the aim of art both to redeem matter and to redeem the will; hence, the importance of following something analogous to a 'rule'; in the sense of answerability, not servility, to standards beyond the self. We can therefore understand form also in terms of discipline. Thus, for example, the use of metrical forms may in itself constitute a kind of ascetic practice.

"For an artist working within a religious perspective," as Sherrard explains, "the forms and images of his art are not his own discovery or invention: they are pre-determined, both on the plane of the imagination and correspondingly in the given canonical prescriptions of his particular religious tradition." He clarifies that "this does not signify that all an artist has to do is slavishly to copy the canonically prescribed forms: such a procedure would at once condemn his art to lifelessness and make it merely academic." (Sherrard 2004, p. 49). Nor, vitally, should a metaphysical or theological framework be imposed upon an artwork, but rather emerge from within it. This is the experience and testimony also of some key modern artists. Pärt's musical reorientation is, like John Tavener's explorations in the same medium, indissolubly artistic and spiritual. To discover the artistic potentials of a medium or a form is to discover its metaphysical implications, and vice versa.

It is through creative practice that an artist may, as it were, test the truth of certain metaphysical or theological propositions. So, McKeever, through profound and painstaking meditations in and on the medium of painting, tests the truth of the claim — embodied in the icon-tradition —-that 'all is from light'. The meaning of this insight or outlook can only be assessed and articulated through the act of painting itself. The worldview in question will only be accepted as valid, by artist and audience alike, if it can be shown to bear creative fruit. We accept the notion that all being springs from and aspires towards the light if, and only if, we see that movement, and that light, manifested in the work of art.

\section{Beauty}

If we expect an artwork to reorient our desire and will towards God, what in the work itself can help us to do this if not, most emphatically, its beauty? It is right to challenge notions of immanent formal perfection, as well as notions of the individual artist as the source of all value in a work. Beauty, crucially, should not be understood either in formalist or subjectivist terms. 
Taking our cue again from Berdyaev, there is a difference between sacred pagan and Christian art. For us, now, in the light of Hart's diagnosis of a world faced with the option of 'Christ or Nothing', we must affirm a sacred art that is Christian rather than pagan in its ontological and aesthetic commitments.

"In classic pagan art," Berdyaev argues, "there is an immanent completeness, an immanent perfection. Classically beautiful pagan art strives for finality and perfection of form here on earth, in this world." (Berdyaev 2009, p. 227). "In the art of the Christian world," however, Berdyaev continues, "there is not, nor can there be, a classic finality of form, immanent perfection [... ] In this world only a striving towards the beauty of another world is possible, only the longing for that beauty. The Christian world permits of no closing-in, no finality in this world."11 The critique of formal and final beauty as incompatible with Christian and theophanic art has also been levelled by C.A. Tsakiridou. Rowan Williams, meanwhile, has written in similar terms about the open-ended fiction of Dostoevsky.

Christian art should be responsive, indeed answerable, both to a historical irruption of liberty and inspiration, and to a pre-existing plenitude of form and beauty that cannot be contained within an immanent frame. The beauty here envisioned is a beauty of which the artwork may partake but not circumscribe or exhaust. In a Christian ontology of participation, a finite work of art may manifest what Hart calls the beauty of the infinite.

We should not expect Christian art, therefore, to strive for formal perfection, but perhaps rather to be elliptical, ecstatic, and epiphanic. Even brokenness, emptiness and silence-as heard, for example, in the music of Pärt-may inform a Christian artwork, the radical openness of which is what allows it to be held up to, and so to harbour and host in return, the uncreated.

We see in McKeever, again, how the forms of his paintings retain a diaphanous fluidity and translucency, in order to intimate rather than imprison an elusive presence. McKeever speaks of the painting emerging out of the relation between his own body and the body of the physical canvas before him. Faced with a blank canvas, he works through abstraction, not towards figuration, but towards form and presence. "'It is,'" he says, "'as if I'm trying to sense an image that is on the other side abstraction and moving away from the abstract rather than towards it.'" (McKeever 2009, p. 24).

Pertinent here is Tsakiridou's understanding of theophanic icons as simultaneously 'kenotic' and 'plerotic', self-emptying and spirit-filled: "Implicit is a movement towards the dissolution and augmentation of form, towards contraction and expansion consistent with the inexhaustible plenitude and withdrawal of the divine presence." (Tsakiridou 2013, p. 251). A theophanic artwork, whatever the medium, thus has an openness in its form, "in order to reveal in ever incomplete moments of being a deeper ground from where an elusive fullness arises." ${ }^{\prime 2}$ We may perhaps speak of 'forms of irruption'; not the deliberate dissolution that characterises so much modern and contemporary art, but forms that manage to reintroduce, into the fragmented fabric of reality, a manifestation of transcendent plenitude.

More than aesthetic, beauty should be understood as a truly ontological manifestation. We can only ever analogously speak of beauty as a visible quality, for example, in poetic, musical, or conceptual works-perhaps, indeed, even in visual works. We can more lucidly and inclusively speak-in the words of David Bentley Hart—of "a handing over and return of the riches of being." (Hart 2003).

Irreducible to formal properties, no less than to dictates of will, this beauty is a gift. It is not created by the human artist. Nor is it simply added to a work after its formal completion, but is always already there as that towards which, within which, and at the prompting of which the artist works. The task of the artist is to peel back the layers of opacity which cover it, using the tools of his medium.

This is the opposite of a voluntarist account of beauty as wilful and subjective. "The beautiful is not a fiction of desire," Hart shows, "nor is its nature exhausted by a phenomenology of pleasure; it can be recognised in despite of desire, or as that toward which desire must be cultivated."13 We may say the same of creativity. Beauty should be the aim and tutor of our creativity no less than our

\footnotetext{
Ibid., p. 228

Ibid., p. 317.

Ibid., p. 17.
} 
desire: so that, within the particular practices of our chosen vocation, we can cultivate a closer and more articulate responsiveness to its real prompting and presence.

The artist needs to 'let beauty happen' and needs discernment to do so. Indeed, it takes skill also to know when and how to allow the gratuitous to take place, to become part of the artistic process and method. If this is true already of traditional practices, it is perhaps especially pertinent for artists that incorporate randomness and nonagency into their works. We can speak of a kind of ontological, not simply aesthetic, responsiveness to the manifestation of irreducible being itself in a particular medium or context.

Any sacred art, any art truly partaking of a sacred reality, is a product of divine-human cooperation. There is no surer sign of this synergy than the artwork's beauty. If we accept a sacred ontology, we cannot but accept beauty as one of its manifestations; and so we cannot but affirm beauty (properly understood as the splendour of being) as one of the aims of art. Sadly, Sherrard suggests, such beauty is "totally rejected by the activities of the secular world and most of what passes for its art." (Sherrard 2004, pp. 20-21). Nevertheless, or rather because of this, we must be committed to it. For it is beauty, above all, that allows us to rediscover a sacred ontology in the midst of a materialist world; not through theoretical study, but through direct experience of the irreducible.

\section{Conclusions}

In secular and postsecular times, the arts must increasingly vindicate a worldview which makes their own practices intelligible, let alone meaningful. Philosophy and theology have a supporting role to play here, to establish the conditions under which an artwork may be received as sacred, but the rediscovery of a committed artistic-spiritual discipline—of creative discipleship—is primary.

Sherrard rightly urges us to "heal the breach between art and metaphysics."14 What is demanded, he suggests, is a kind of renunciation; a withdrawal from the superficially cultural battle in order to rediscover "that spiritual capital of which the art and life of our post-medieval world have been first the exploitation, then the dissipation, and finally the exhaustion."15

The challenge remains, however, to create art that is meaningful and intelligible here and now. Cultural knowledge will inevitably be subject to entropy. Regardless of this, or because of it, the artist must always find new ways of enabling communion between past and present, as well as between the created and uncreated. Any art with sacred ambitions must, in some manner and measure, become incarnate in the prevalent, postsacral and postsecular culture, even in order to leaven that culture with realities it has exiled and occluded.

Crucially, a metaphysical worldview should not be presented to the audience as an intellectual hypothesis. If an artwork is to be capable of granting an experience of existential and ontological re-orientation, then the work cannot simply be the expression of an antecedent proposition. We cannot expect readers, listeners, or viewers to accept a worldview that is not borne out, not embodied, by the artworks themselves. We need to withdraw into, in order to draw from, not only into the metaphysical but also the artistic traditions, their mediums and materials. We need to rethink originality as faithfulness to the origins (and therefore ends) of art. "We can and must go to the fount of things, can and must make all things new."16

It may indeed be that the more we come to understand, for example, what poetic language and poetic form are truly capable of, the more we may also grasp the potentials of our own creative humanity. To trace poetic art to its first principles and utterances is to arrive at mythopoeia, at prophecy, at prayer and praise; it is to arrive where aesthetics and metaphysics are indeed indissoluble. To trace

\footnotetext{
14 Ibid., p. 157

15 Ibid., p. 35.

16 Ibid., p. 156.
} 
visual art back to its first principles is to become ever deeper involved in a world in which sacramental re-presentation and new creation are possible.

The aim of art (of sacred art in particular) should be, as also C.A. Tsakiridou argues, to articulate and embody life. Tsakiridou singles out Rothko as a painter in whose work "representation becomes irrelevant" "because it is not 'art' anymore" but "has become a living reality." (Tsakiridou 2013, p. 276). Among contemporary visual artists, Ian McKeever is exemplary in his exploration-significantly inspired by the icon-tradition-of what painting is and can be.

Much is at stake. For we find ourselves in the midst of a conflict, not only of cultural values, but of ontological conceptions and commitments. Thus, Kordis seeks to address and assuage "the needs of contemporary people [who are] tortured by the void of relationships and the abyss of darkness." (Kordis 2019). McKeever, meanwhile, claims that a painter paints either towards the darkness or towards the light. This is true, of all the arts, in more senses than one. The aim of contemporary and future makers must be to choose the latter course: to pursue creative work as the revelatory and regenerative participation in an ontology of light.

Funding: This research received no external funding.

Conflicts of Interest: The authors declare no conflict of interest.

\section{References}

Berdyaev, Nikolai. 2009. The Meaning of the Creative Act. Translated by Boris Jakim. San Rafael: Semantron Press. Džalto, Davor. 2014. The Human Work of Art. Yonkers: SVS Press.

Eliot, Thomas Stearns. 1944. The Four Quartets. London: Faber \& Faber.

Florensky, Pavel Aleksandrovich. 1996. Iconostasis. Translated by Donald Sheehan, and Olga Andrejev. Crestwood: SVS Press.

Hart, David Bentley. 2003. The Beauty of the Infinite. Grand Rapids: Eerdmans.

Hart, David Bentley. 2009. In the Aftermath. Grand Rapids: Eerdmans.

Hart, David Bentley. 2017. The Hidden and the Manifest. Grand Rapids: Eerdmans.

Heaney, Seamus. 2015. New Selected Poems. London: Faber \& Faber.

Kordis, George. 2019. My Painting. Available online: http://kordis.gallery/about/ (accessed on 18 January 2019). Louth, Vladimir. 2013. Introducing Orthodox Theology. London: SPCK.

McKeever, Ian. 2002. William Blake's 'Jerusalem', the Emanation of the Giant Albion. London: Alan Cristea Gallery.

McKeever, Ian. 2009. Paintings. Edited by Marjorie Allthorpe-Guyton, Michael Tucker and Catherine Lampert. Farnham: Lund Humphries.

Pasternak, Boris. 2011. Doctor Zhivago. Translated by Richard Pevear, and Larissa Volokhonsky. London: Vintage. Scruton, Roger. 2009. Beauty. Oxford: Oxford University Press.

Sherrard, Philip. 2004. The Sacred in Art and Life. Limni: Denise Harvey.

Tsakiridou, Cornelia A. 2013. Icons in Time, Persons in Eternity. Farnham: Ashgate.

Williams, Rowan. 2005. Grace and Necessity. London: Continuum.

(C) 2019 by the author. Licensee MDPI, Basel, Switzerland. This article is an open access article distributed under the terms and conditions of the Creative Commons Attribution (CC BY) license (http://creativecommons.org/licenses/by/4.0/). 